\title{
Inhibition of associates and activation of synonyms in the rare-word paradigm: Further evidence for a center-surround mechanism
}

\author{
TERRENCE M. BARNHARDT, ELIZABETH L. GLISKY, \\ MICHAEL R. POLSTER, and LAURIE ELAM \\ University of Arizona, Tucson, Arizona
}

\begin{abstract}
Two experiments investigated semantic priming effects in a modified version of the Dagenbach, Carr, and Barnhardt (1990) rare-word paradigm. After learning a list of rare words to a criterion of $50 \%$ recall, subjects participated in a lexical decision task in which the rare words served as primes. When the targets were associatively related to the primes, lexical decision responses were facilitated following recalled definitions and inhibited following unrecalled definitions. When the targets were synonyms of the rare words, facilitation occurred following both recalled and unrecalled definitions. The results were interpreted as supporting a center-surround model of attentional retrieval that may serve an adaptive role in new learning.
\end{abstract}

Knowledge concerning the meanings of words has usually been attributed to a functionally distinct system known variously as lexical memory (Oldfield, 1966), generic memory (Hintzman, 1978), or semantic memory (Tulving, 1972). Access to a word's meaning on the basis of its orthographic or phonological code appears to occur rapidly and automatically, and appears also to activate the representations of semantically related words. This latter phenomenon, known as semantic priming (see, e.g., Meyer \& Schvaneveldt, 1971), has been studied extensively and has prompted a number of theoretical formulations concerning the organizational structure of and processes associated with the semantic memory system (see Neely, 1991, for review).

In the standard semantic priming paradigm (Neely, 1977), subjects are required to make a lexical decision to the second of two consecutive letter strings. When both strings are words, subjects are faster to respond when the words are semantically related than when they are not. Such semantic priming effects have usually been interpreted within a spreading activation model of semantic memory (Collins \& Loftus, 1975). According to this model, concepts are connected by pathways that vary in

This research was supported in part by National Institute on Aging Grant AG09195 to E.L.G., Grant MH 35856 from the National Institute of Mental Health to John Kihlstrom and the McDonnell-Pew Center for Cognitive Neuroscience. The authors would like to thank John Kihlstrom and Tom Carr for their support, Ken Forster for his helpful advice, Cyma Van Petten for her assistance with stimulus creation, and Amy Plotz, Laurel Remers, and Alysha Teed for their assistance with data collection. Terry Barnhardt is now at the University of Illinois, Champaign-Urbana. Correspondence should be addressed to T.M.B., Department of Psychology, University of Illinois, 603 East Daniel St., Champaign, IL 61820 (e-mail: tbarhar@p300.cpl.uiuc.edu). length according to their degree of semantic relatedness: Highly related concepts are close in semantic space and unrelated concepts are far apart. When any particular concept is activated, activation spreads along the pathways to related nodes such that concepts close in space benefit more than distant concepts. In the semantic priming paradigm, activation spreads from the prime to the related target node, which can then be accessed more quickly so that lexical decisions are speeded. This spread of activation appears to occur automatically.

Posner and Snyder (1975a, 1975b) proposed, however, that in addition to an automatic spreading activation mechanism, strategic or attentional processes that reflect the expectations or intentions of the subject may also be involved in semantic priming. These theoretical ideas received empirical support in a series of studies by Neely (1977) in which he manipulated the expectations of the subjects and the prime-target stimulus onset asynchronies (SOAs). At short SOAs (i.e., $250 \mathrm{msec}$ ), expectations concerning the type of targets had no effect on the standard semantic priming effects: Related targets were facilitated and unrelated targets were unaffected, consistent with the operation of an automatic activation mechanism. At long SOAs (i.e., $2,000 \mathrm{msec}$ ), however, expectations determined the pattern of findings. Responses to expected but unrelated targets were speeded whereas responses to unexpected, related targets were inhibited. Neely proposed that these latter effects were attributable to a strategic mechanism whereby attention was focused on expected (and, in this case, unrelated) representations. If the expected unrelated target was then presented, response times were speeded; if, however, a related target appeared, attention had to be switched from the expected to an unexpected representation and re- 
sponse times were therefore slowed. Inhibition thus appeared to be a consequence of unfulfilled expectations.

Inhibition between semantically related items has also been demonstrated when subjects are instructed to ignore a prime (Tipper, 1985; Tipper \& Driver, 1988). For example, Tipper (1985) instructed subjects to remember one and ignore the other of two primes presented simultaneously. On a subsequent naming task, inhibition was observed when target items were either identical to or related to the ignored prime, a phenomenon that Tipper referred to as negative priming. As in the Neely experiments, inhibition appeared to depend on the operation of a strategic process (in this case, ignoring the prime), which apparently served to retard access to representations related to the ignored item (see also Houghton \& Tipper, 1994).

More recently, Dagenbach and colleagues (Dagenbach, Carr, \& Barnhardt, 1990) reported inhibition for semantically related items when subjects were neither instructed to expect unrelated items nor told to ignore related primes. In these experiments, subjects first attempted to learn the definitions of rare words and then participated in a standard semantic priming task in which the rare words served as primes. Lexical decision times were analyzed according to an item's classification in one of four critical cells created by the crossing of two orthogonal factors: prime-target relation (related vs. unrelated) and accuracy with which the definition of the rare word was recalled (recalled vs. unrecalled).

Although Dagenbach, Carr, and Barnhardt (1990) observed normal semantic priming when definitions of the prime words were recalled, lexical decision times were slowed when definitions of the related primes could not be recalled (but were recognizable) - a phenomenon that we will refer to as semantic inhibition. Use of the term "semantic inhibition" is not meant, in itself, to convey anything about the linderlying mechanism to which the relative slowing may be attributed. Semantic inhibition may be attributable to a variety of mechanisms, only one of which is decreased activation of the target representation, or "true" inhibition (see Anderson \& Bjork, 1993). In order to account for this effect, however, the authors did indeed propose the existence of true semantic inhibition in the form of reciprocal lateral inhibitory connections in semantic memory. This mechanism may serve an adaptive purpose in the early stages of learning by protecting weakly represented information from interference by closely related but incorrect information. As learning progresses and codes become more firmly established, however, a change from inhibition to facilitation might be expected to occur. Dagenbach, Carr, and Barnhardt (1990) found some evidence to support this hypothesis in one experiment but failed to replicate the finding subsequently.

At the physiological level, lateral inhibitory mechanisms consist of two parallel channels connected to each other by means of inhibitory interneurons. As a result of the inhibitory connections, increments in the level of ac- tivation in one channel automatically decrease the level of activation in the other channel. In the Dagenbach, Carr, and Barnhardt (1990) model, the effect of lateral inhibition is to increase activation of information at the center of attention and dampen activation of surrounding related information. This produces a topography of activation and inhibition whose configuration is similar to the pattern of optimal stimulation in an (on)center-(off) surround receptive field.

Lateral inhibition has been used to account for the correlation between the patterns of stimulation in (on) center-(off)surround retinotopic receptive fields and the activity in the retinal ganglion cells (e.g., Wiesel \& Hubel, 1960). In this type of receptive field, the center is a circular region with excitatory connections to the ganglionic cell and the surround is a ring around the center with inhibitory connections to the ganglionic cell. When the center is relatively illuminated, this channel increases both direct excitation of the ganglionic cell and the interneuronal inhibition of the inhibitory surround channel. As a result, there is an increase in the ganglionic cell firing rate. In contrast, when the amount of light decreases or increases across the whole receptive field, the ganglionic cell maintains a baseline rate of firing. In this context, the computational purpose of lateral inhibition is to ensure that an activational difference between the center and surround is present before the rate of ganglionic cell firing increases.

In much the same way that an (on)center-(off)surround pattern of illumination in the receptive field increases the firing rate of the ganglionic cell in the Wiesel and Hubel (1960) model, the pattern of center activation and surround inhibition in semantic memory increases target retrievability in the Dagenbach, Carr, and Barnhardt (1990) model. Inspired by these similarities, Dagenbach and his colleagues have referred to their model as a center-surround mechanism. We will also refer to this as a center-surround mechanism, despite the fact that lateral inhibition merely monitors center-surround luminance differences in receptive fields, whereas it actually produces center-surround activational differences in semantic memory.

Another model that features lateral inhibition is that of Walley and Weiden (1973). In this model, reciprocal lateral inhibition produces selective attention during pattern recognition. Walley and Weiden hypothesized that preattentive pattern recognition of a number of different inputs was accomplished in parallel by a hierarchical network of feature analyzers that passed activation up to a final layer consisting of categorical units. Activation of any particular unit in this layer constituted construction of an internal representation of the input. Reciprocal lateral inhibition was used in this layer to select the most active categorical unit by increasing activation of the relatively more active units and decreasing activation of the others.

Unlike the Walley and Weiden (1960) model, attention in the Dagenbach, Carr, and Barnhardt (1990; Carr \& 
Dagenbach, 1990) model is an independent top-down process that serves two purposes. First, it focuses retrieval on a semantic level of representation. Second, it engages the lateral inhibition mechanism in an area of semantic space to which it has been attracted by bottomup activation. Despite this difference, the computational goal of the lateral inhibition mechanism proposed by $\mathrm{Da}-$ genbach, Carr, and Barnhardt (1990; Carr \& Dagenbach, 1990 ) is similar to that in the Walley and Weiden (1960) model. That is, when an attempt is made to retrieve new information that is weakly represented in semantic memory, the code that is most strongly activated by bottomup processes is protected from interference from (nearby) related representations.

As noted earlier, although the center-surround mechanism is a plausible theoretical explanation for the semantic inhibition observed when definitions are unrecalled, an alternative interpretation is possible. Semantic inhibition may also be attributable to a type of response interference. If, when unable to recollect the definition of a rare-word prime, a subject is reminded of the definition when the related target appears, processing of this information may take time, thus slowing the lexical decision response to the target.

One way to distinguish between these explanationscenter-surround and response interference-may be to control the nature of the semantic relation between the prime and target instead of using a variety of primetarget relations as Dagenbach, Carr, and Barnhardt (1990) did. The response interference account predicts inhibition following unrecalled definitions regardless of the target's relation to the prime. Subjects should be just as surprised to see a synonym as an associate of the unrecalled word.

The center-surround account, however, makes different predictions for associatively and synonymously related prime-target pairs. As noted, in the semantic space described by Collins and Loftus (1975), related concepts (e.g., associates) were close and unrelated concepts were distant. In designing the present set of experiments, we made two additional assumptions regarding the nature of semantic space. First, we assumed that synonyms were the most highly related concepts and that they should be closer in semantic space than associates. Second, we assumed that a synonym of a definition, given its relative proximity, would fall in the center of the center-surround field, whereas an associate to the definition, given its relative distance, would fall in the surround. If these assumptions are correct, and the center-surround mechanism protects weakly represented information from interference from related but incorrect codes, semantic inhibition should be observed for associatively related stimuli, whereas facilitation should be observed for synonymously related stimuli.

We designed the present experiments to test these alternative explanations of the semantic inhibition effect in the rare-word paradigm by varying the nature of the prime-target relation. Because of the need to create two sets of stimuli-one consisting entirely of rare words with associative targets and the other consisting of rare words with synonymous targets - an initial normative study was conducted to obtain the necessary materials.

\section{NORMATIVE EXPERIMENT}

The purpose of the normative study was to obtain sets of associatively and synonymously related prime-target pairs that produced semantic priming. Dagenbach, Carr, and Barnhardt (1990) used pairs that were related in a variety of ways, but they did not obtain normative data that established whether the definitions would in fact prime the targets in a standard semantic priming paradigm.

Although the nominal primes were the rare words in the rare-word paradigm developed by Dagenbach, Carr, and Barnhardt (1990), subjects were instructed to try to recall the definitions of those words while waiting for the lexical decision targets to appear. The definitions of the rare words, therefore, were the functional primes. For that reason, the definitions of rare words served as primes in the normative study.

Short definitions of 396 rare words were selected along with three different word targets, each of which was either associatively or synonymously related to that definition. The stimulus set thus consisted of 1,188 pairs of rare word definitions and related word targets. Three separate lists were constructed, each consisting of all the rare word definitions and one of their corresponding word targets. Each of 126 subjects was tested with one of the 396-item lists in a standard semantic priming paradigm. Each subject saw all of the definitions, and each of the three targets was tested equally often across subjects. The design was fully counterbalanced so that across subjects and lists each of the definitions was followed equally often by a related target, an unrelated target, and a nonword. Unrelated targets were generated by rotating targets through blocks of items such that no target was seen more than once by any single subject. Nonwords were pronounceable, orthographically legal letter strings.

Definitions were studied for $3 \mathrm{sec}$ and were followed $650 \mathrm{msec}$ later by a target to which subjects made a lexical decision by pressing one of two keys on the computer keyboard. After data from 20 subjects were eliminated (because of error rates higher than 15\%), reaction times (RTs) from the remaining 106 subjects were analyzed, and 104 prime-target pairs were selected for each of two experiments. Set 1 consisted of associatively related pairs and set 2 consisted of synonymously related pairs. The basic criteria for selection were that the definitions primed the targets (i.e., the RTs to a target were faster when it was related to the prime than when it was unrelated) and that the targets bore the appropriate relation to the prime for each list (i.e., either associate or synonym). The exact criteria for selection were somewhat different for the two lists so that the mean priming effect would be approximately equivalent across the two sets of items. More detailed descriptions of the selection 
procedures and of the stimuli appear in the materials sections of each of the two experiments.

\section{EXPERIMENT 1}

The goal of Experiment 1 was to replicate Dagenbach, Carr, and Barnhardt's (1990) finding of semantic inhibition following unrecalled related primes with the associatively related materials obtained from the normative study. A number of procedural changes were made to the methodology in order to avoid some of the problems that Dagenbach et al. encountered.

As mentioned earlier, in the rare-word paradigm, items are analyzed according to their classification in four critical cells: recalled/related (RC/REL), recalled/ unrelated (RC/UNR), unrecalled/related (UNRC/REL), and unrecalled/unrelated (UNRC/UNREL). The number of observations in these cells cannot be determined preexperimentally because it depends on the recall performance of individual subjects. If the recall rate for any subject is very high or very low, there may be too few observations in one or more of the four cells to support meaningful analyses. Even though Dagenbach, Carr, and Barnhardt (1990) required only three observations per cell, they still had to discard between $33 \%$ and $61 \%$ of their subjects across experiments. In order to avoid this problem, we employed a learning procedure in which subjects learned the definitions of rare words to a recall criterion of approximately $50 \%$ before they proceeded to the lexical decision test. We expected that this would reduce the likelihood of discarding or replacing subjects and would allow us to raise the minimum number of observations per cell from 3 to 7 .

Another problem in the Dagenbach, Carr, and Barnhardt (1990) experiments concerned the possibility of test priming effects (Shimamura, 1985). Recall of the definitions was measured after the lexical decision task. To the extent that related lexical decision trials may have acted as additional study opportunities, some items that were remembered on the recall test may actually have been unrecalled at the time of the lexical decision task. We avoided this problem in the present experiments by presenting the recall test prior to the lexical decision task.

\section{Method}

Subjects. Forty introductory psychology students participated in this experiment in order to meet a course requirement or to receive extra credit. Each subject completed two sessions that were separated by at least 1 intervening day. The procedure was identical on both days; only the materials differed.

Materials and Apparatus. The materials consisted of 104 rare words and their associatively related targets as selected from the normative study (see Appendix). The following criteria were used for selection: (1) RTs were faster when the target followed a related definition than an unrelated definition. (2) The difference between the unrelated and related RTs yielded a two-tailed $t$-test value of at least 90 . Despite the fact that $t$-test values are influenced by the number of observations, it seemed better to use a statistic that accounted for the variability in the two conditions than to simply use the difference. (3) Only definition-target pairs whose mean related
RT was not higher than the overall related mean and whose mean unrelated RT was not higher than the overall unrelated mean were selected. This criterion was designed to avoid the possibility that inhibition of unrelated items was responsible for the RT difference between the unrelated and related conditions. (4) The amount of semantic overlap between different pairs of items was minimal. (5) No target word appeared in any definition. The targets that constituted the final 104-item list produced a mean RT of $554 \mathrm{msec}$ following a related definition and a mean RT of $663 \mathrm{msec}$ following an unrelated definition, thereby yielding a mean priming effect of $109 \mathrm{msec}$.

The 104 new vocabulary words were divided into two lists of 52 items. Each subject studied a different list on each day, with order of presentation counterbalanced across subjects. Ten other rare words and their definitions were used as primacy and recency buffers in the learning phase, 5 on each day.

The lexical decision task consisted of the 52 rare-word primes that had been studied in the first phase of the experiment, followed by 52 targets for lexical decision: 13 related to the rare-word definition, 13 unrelated to the definition, and 26 nonwords. The assignment of a rare-word prime to one of the three conditions was counterbalanced across subjects. Unrelated prime-target pairs were formed via the exchange of targets related to rare words in the unrelated condition of one list with targets related to rare words in the unrelated condition of the other list. This procedure ensured that subjects never saw the same target twice (even across days). Nonwords were pronounceable, orthographically legal, letter strings that were constructed by combining syllabic elements from real words and that were at least two letters different from any English word.

Stimulus presentation and response collection for all phases of the experiment were conducted on an IBM-compatible AT microcomputer and were controlled by software routines we constructed using MEL (Micro Experimental Laboratory).

Procedure. In the first phase of the experiment, subjects were instructed to try to learn the definitions of 52 rare words in anticipation of a later memory task. They were told to try to learn the definitions as precisely as possible. Each word and its definition appeared on the computer screen for $7 \mathrm{sec}$, preceded by a $400-\mathrm{msec}$ warning tone and followed by a $350-$ msec blank screen. The 52-item list was presented twice in a different random order on each presentation. After the second presentation, subjects were engaged in a 3-min filler task in which they completed fragments of geographical entities (e.g., A__an_ic Ocean).

A recall test followed the filler task. The rare words were presented one at a time in random order in the center of the computer screen for $5 \mathrm{sec}$ accompanied by a warning signal lasting $400 \mathrm{msec}$. Subjects were instructed to state aloud the definition within the 5 sec period, and their responses were recorded. The time limit was imposed in order to minimize the discrepancy between the amount of time subjects had to recall definitions in the recall and lexical decision tasks. This makes it more likely that the status of a definition (i.e., unrecalled or recalled) established at the time of the recall test was reproduced at the time of the lexical decision task. An experimenter who was thoroughly familiar with all of the definitions scored each response on-line as correct or incorrect in order to determine the overall level of recall. If recall was within 6 items of the criterion of $50 \%$ recall (i.e., $26 \pm 6$ ), subjects proceeded to the lexical decision phase of the experiment. If recall was less than $26 \pm 6$ items, the list was presented for study and test again until the $50 \%$ criterion was reached. No subject saw the list of items more than four times.

All subjects advanced to the lexical decision phase of the experiment, whether or not they fell within the recall criterion window. The sequence of events on each lexical decision trial was as follows: A fixation cross appeared for $350 \mathrm{msec}$ followed by a blank screen lasting $200 \mathrm{msec}$. The rare-word prime was then pre- 
sented for $1,800 \mathrm{msec}$, followed by a 500 -msec blank screen. Then the target appeared and remained on the screen until the subject made a response. The start of the next trial followed a $750-\mathrm{msec}$ blank screen. Subjects responded by pressing the L key if the letter string was a word and the S key if the letter string was a nonword. Incorrect responses were signaled by a low tone from the computer. Subjects were instructed to try to think of the definition of the rare word when it appeared on the screen, but were not told to use the definition to anticipate the target. Subjects were instructed to make their lexical decision responses to the target as quickly and accurately as possible. A practice block, which consisted of 12 trials containing common word primes along with related, unrelated, and nonword targets, preceded the block of critical trials.

After the lexical decision task, subjects were administered a recognition test to ensure that all rare words and their definitions were at least partly learned and were therefore represented in semantic memory even though the definitions could not be recalled. Dagenbach et al. (1990) had suggested that unrecognized items would have no representation in semantic memory and should be excluded from the analysis. On the basis of pilot work, we expected that recognition would be close to $100 \%$ and therefore planned to include all items in the analysis. The recognition test served primarily as a confirmation that recognition performance was close to ceiling, as expected. The test required a choice among four alternatives: the correct definition, the definition of another rare word studied that day, and two definitions of rare words that were not part of the 104-item set. The test items appeared on the computer screen in a different random order for each subject. Subjects worked through the list at their own pace.

\section{Results}

Preliminary analyses. Lexical decision error trials were eliminated from further analyses, along with trials in which RTs were less than $150 \mathrm{msec}$ or greater than $1,500 \mathrm{msec}$. The remaining data were aggregated across the 2 days of testing. Three subjects were eliminated because their overall lexical decision error rate was greater than $15 \%$. Five subjects were eliminated because fewer than 7 observations were collected in one or more of the critical cells across the 2 days. These 8 subjects were replaced so that the complete counterbalancing was maintained. All subsequent analyses were conducted on data from 32 subjects.

As expected, recognition performance was high $(M=$ $98.4 \%$ ). As a result, no items were eliminated from the analysis because of recognition failure. Examination of the recall performance when it was summed across days indicated that we were reasonably successful in achieving our criterion of $50 \%$ recall and in eliminating the test priming bias. Subjects recalled an average of 12.5 (out of a possible 26) definitions in both the related and unrelated conditions. Examination of the single day recall performance revealed that most subjects provided a substantial number of observations in all of the critical cells on any single day of testing $(M=6.2 ; S D=2.0)$.

Semantic priming. The main analyses concerned the effects of semantic relatedness in the lexical decision task for recalled and unrecalled primes. The mean RTs, standard deviations, and error rates for each of the four critical cells, along with the two nonword cells (i.e., RC/ NW and URC/NW), are displayed in Table 1. As can be seen from the table, when definitions of the rare words
Table 1

Mean Lexical Decision Response Times (in Milliseconds) as a Function of Recall and Relation for Associatively Related Targets

\begin{tabular}{lrcccccc}
\hline & \multicolumn{3}{c}{ Unrecalled } & & \multicolumn{3}{c}{ Recalled } \\
\cline { 2 - 3 } \cline { 6 - 8 } Relation & RT & $S D$ & PE & & RT & $S D$ & PE \\
Related & 665 & 85.6 & 4.9 & 649 & 79.8 & 2.1 \\
Unrelated & 642 & 82.7 & 4.4 & 675 & 77.3 & 5.0 \\
Difference & -23 & & & +26 & & \\
Nonword & 748 & 98.1 & 5.6 & 731 & 94.6 & 5.3 \\
\hline
\end{tabular}

Note-Difference $=$ Unrelated - Related; RT, response time; $S D$, standard deviation; PE, percent error.

were recalled, lexical decision times to related targets were facilitated by $26 \mathrm{msec}$ relative to unrelated targets. Conversely, when definitions were unrecalled, lexical decision times to related targets were inhibited by $23 \mathrm{msec}$. A $2 \times 2$ repeated measures analysis of variance (ANOVA) confirmed the significant interaction between recall and relation $\left[F(1,31)=20.07, M S_{\mathrm{e}}=986.77, p<.001\right]$ and indicated no main effects of either variable. An analysis of the simple effects revealed both significant facilitation for targets following recalled primes $[F(1,31)=$ $\left.10.57, M S_{\mathrm{e}}=1,085.22, p<.005\right]$ and significant inhibition for targets following unrecalled primes $[F(1,31)=$ $\left.8.12, M S_{\mathrm{e}}=1,039.50, p<.01\right]$.

\section{Discussion}

The pattern of results in the present experiment replicated the findings reported by Dagenbach, Carr, and Barnhardt (1990, Experiment 2): Facilitation was observed for targets related to rare words whose definitions were recalled, and inhibition was observed for targets related to rare words whose definitions were not recalled. The results also indicated that the methodological changes that were incorporated into the paradigm reduced subject attrition rates, increased the number of observations per cell, and removed potential test priming biases.

Before exploring the theoretical implications of these findings, we first considered whether any aspects of our methodology might explain the results. The inhibition observed when definitions were unrecalled might be attributable to the fact that subjects were still attempting to retrieve the definition when the target appeared. If this were the case, however, similar slowing should have occurred for unrelated as well as related trials; this clearly did not happen. Second, because neutral trials were not included, the priming in the recalled condition could have resulted either from inhibition in unrelated trials or from facilitation in related trials, or both. However, if unrelated trials were inhibited, the size of the inhibition effect in the unrecalled condition (i.e., the observation of most interest) was underestimated.

The replication of the Dagenbach, Carr, and Barnhardt (1990) findings with a set of associatively related prime-target pairs provides further evidence for the semantic inhibition effect in the rare-word paradigm, but does not distinguish among the different theoretical in- 
terpretations. Both explanations - center-surround and response interference-can account for inhibition of associates of unrecalled definitions. The critical test of these alternatives is provided in Experiment 2.

\section{EXPERIMENT 2}

Although either of the two proposed interpretations of the semantic inhibition effect can explain the finding of inhibition for associates of unrecalled definitions, they make different predictions with respect to synonymously related stimuli. The center-surround theory states that when definitions cannot be recalled, information that is at the focus of the retrieval attempts is activated whereas surrounding related information is inhibited. If synonyms fall within the center of the center-surround mechanism, they should escape the inhibition that befalls associated concepts that lie outside of the center. Further, if the center region of the proposed mechanism is activated, responses to synonyms should even be facilitated. In contrast, the response interference account predicts that inhibition should be observed when definitions are unrecalled, whether synonyms or associates serve as the related target words.

\section{Method}

Subjects. Forty-three introductory psychology students who had not taken part in Experiment 1 participated in this experiment in order to meet a course requirement or to receive extra credit. Each subject completed two sessions that were separated by at least 1 intervening day. The procedure was identical on both days; only the materials differed.

Materials. The materials consisted of 104 rare words and their synonymously related targets as selected from the normative study (see Appendix). Synonymity was operationally defined in the following manner: If the authors judged that an image of the definition and an image of the target were the same, then the target was classified as a synonym of the definition (e.g., having a rough texture-coarse). Although we attempted to select pairs that were bidirectionally synonymous, this was not always possible. We adopted a slightly more liberal set of guidelines to select the prime-target pairs in this experiment than in Experiment 1 because there were fewer synonymous targets in the normative study. The minimum two-tailed $t$-test value for the comparison between related and unrelated RTs was lowered to .2, and no limitations were placed on the absolute values of the RTs observed in either the related or unrelated conditions. Seventeen of the rare words used in Experiment 1 were also used in this study. The targets that constituted the final 104-item list produced a mean RT of $615 \mathrm{msec}$ following a related definition and a mean RT of $728 \mathrm{msec}$ following an unrelated definition, thereby yielding a mean priming effect of $113 \mathrm{msec}$ (compared to $109 \mathrm{msec}$ in Experiment 1). All other details of stimulus selection and counterbalancing were the same as those in Experiment 1.

Procedure. The procedure used in this experiment was identical to the one used in Experiment 1 except for some time constraints that prevented some subjects from receiving more than two exposures to the rare-word list in the study phase. This limitation resulted in a slightly increased subject deletion rate, as noted below.

\section{Results}

Preliminary analyses. Five subjects were eliminated because their overall lexical decision error rate was
Table 2

Mean Lexical Decision Response Times (in Milliseconds) as a Function of Recall and Relation for Synonymously Related Targets

\begin{tabular}{lrrrrrrrr} 
& \multicolumn{3}{c}{ Unrecalled } & & \multicolumn{3}{c}{ Recalled } \\
\cline { 2 - 4 } \cline { 6 - 8 } Relation & RT & $S D$ & PE & & RT & $S D$ & PE \\
\hline Related & 727 & 124.1 & 7.0 & & 713 & 115.8 & 6.4 \\
Unrelated & 748 & 139.6 & 10.0 & & 738 & 123.0 & 13.9 \\
Difference & +21 & & & & +25 & & & \\
Nonword & 804 & 142.1 & 11.2 & & 792 & 142.6 & 8.6 \\
\hline
\end{tabular}

Note-Difference $=$ Unrelated - Related; RT, response time; $S D$, standard deviation; PE, percent error.

greater than $15 \%$. Six subjects were eliminated because fewer than 7 observations were collected in one or more of the critical cells across the 2 days. All of these subjects had too few observations in one of the recalled cells. These 11 subjects were replaced so that the complete counterbalancing was maintained and all subsequent analyses were conducted on data from 32 subjects. Recognition performance was again high $(M=98.8 \%)$ and no items were eliminated because of recognition failures. Single day recall performance was substantial $(M=5.9 ; S D=1.9)$ and the $50 \%$ recall criterion was approximated: Subjects recalled an average of 12.1 definitions in the related condition and 11.6 in the unrelated condition.

Semantic priming. The mean RTs, standard deviations, and error rates for each of the four critical cells, along with the two nonword cells, are shown in Table 2 . As can be seen from the table, facilitation (UNREL REL) was observed in both the recalled $(25-\mathrm{msec})$ and unrecalled $(21-\mathrm{msec})$ conditions. A $2 \times 2(\mathrm{RC} \times \mathrm{REL})$ repeated measures ANOVA revealed that the only significant effect was a main effect of relation $[F(1,31)=$ $\left.5.88, M S_{\mathrm{e}}=2,824.29, p<.05\right]$. This result contrasts with the findings of Experiment 1, in which RTs to associate targets were facilitated following recalled definitions $(+26 \mathrm{msec})$ but inhibited following unrecalled definitions $(-23 \mathrm{msec})$.

\section{GENERAL DISCUSSION}

The results from the present experiments replicate and extend those reported by Dagenbach et al. (Dagenbach, Carr, \& Barnhardt, 1990; Dagenbach, Carr, \& Wilhelmson, 1989; Dagenbach, Horst, \& Carr, 1990). In doing so, they (1) provide additional empirical support for an inhibitory center-surround mechanism; (2) suggest that the mechanism reflects automatic, rather than controlled, processing; (3) suggest that the mechanism operates at the level of semantic memory; and (4) raise some interesting speculations concerning the processes involved in the acquisition of new vocabulary. We will discuss each of these issues in turn.

The contrasting pattern of findings in Experiments 1 and 2 provides compelling evidence that the inhibition for associates of unrecalled definitions is not attributable 
to response inhibition (Tipper \& Cranston, 1985). Rather, the semantic inhibition appears to be attributable to the operation of a center-surround mechanism in which activation of the functional prime is heightened and activation of concepts related to the functional prime is dampened (Dagenbach, Carr, \& Barnhardt, 1990). Whereas the former explanation predicts inhibition following any unrecalled definition regardless of the primetarget relation, a center-surround explanation predicts inhibition for associatively related targets and facilitation for synonymously related targets. The data in the present experiments clearly support the center-surround interpretation.

The prime-target SOA in our experiments was $2,300 \mathrm{msec}$, allowing plenty of time for subjects to engage controlled processing and attempt to retrieve definitions of the primes. When definitions were not retrieved, however, the resulting inhibition on related words probably occurred automatically. Given subjects' failure to identify the centered representation (i.e., the definition), intentional inhibition of related representations seems improbable. It also seems unlikely that attention is attracted to the weakly activated definition and targets it for the center-surround mechanism in a very precise manner. It seems more likely that, once attention has focused retrieval on a semantic level of representation, the center-surround mechanism is automatically engaged by the relatively widespread distribution of activation. In this respect, we envision the center-surround mechanism in a slightly different manner than that described by Carr and Dagenbach (1990; Dagenbach \& Carr, 1994).

In other studies demonstrating semantic inhibition, the inhibitory process has usually been attributed to a controlled rather than an automatic mechanism. For example, Neely (1977) reported inhibition only when subjects were led to expect targets from one category and were then presented with items from another category. In the Tipper (1985) experiments, inhibition occurred when subjects were explicitly instructed to ignore the prime. Neither of these paradigms, however, appear to involve a center-surround mechanism. In the Neely experiments, unlike the present experiments, inhibition was observed following an activated functional prime that was unrelated, rather than related to the target. In the Tipper experiments, both the center (i.e., targets identical to the prime) and the surround (i.e., targets related to the prime) were inhibited.

Even in the conceptually similar primed tip-of-thetongue (TOT) experiments, in which a center-surround mechanism might be invoked, the semantic inhibition is not automatically elicited. In the standard TOT paradigm, subjects are asked to generate a word when presented with its definition (e.g., Brown \& McNeil, 1966). In primed TOT experiments, the definition is preceded by a word related to the target, and inhibition of the target response is observed (Brown, 1979). This inhibitory effect, however, is obtained only when trials are included in which primes are identical to the target (Roediger,
Neely, \& Blaxton, 1983). In this case, an effective strategy might be to inhibit words related to the presented prime to prevent their intrusion when the prime exactly specifies the target item. When the target is related instead of identical to the prime, however, the inhibition affects the target response and produces the TOT state. The center-surround mechanism in the primed TOT studies may thereby be invoked as the result of a strategic, rather than an automatic, process.

The present results also suggest that the inhibition effect is localized in semantic memory rather than in episodic memory because it occurs in the absence of episodic recall. The failure to retrieve the rare word definition makes it unlikely that any episodic information is accounting for the inhibition. For example, if a subject is unable to recall hawk when presented with the rare word accipiter, there is no episodic pointer to inhibited representations like eagle. The inhibition therefore appears to occur at the level of the semantic memory system. This implies that some representation of the association between accipiter and hawk was laid down in semantic memory even though it could not be recalled episodically. This finding suggests that the semantic system may be able to acquire some knowledge directly without representation in the episodic system, a phenomenon that has been proposed to account for learning by amnesic patients who lack episodic memories (Glisky, 1992; Tulving, Hayman, \& Macdonald, 1991; Warrington \& McCarthy, 1988).

In contrast, the facilitation observed for recalled items is probably a function of both episodic and semantic mediation. If new associations (e.g., accipiter-hawk) are integrated into the semantic network early in the learning process, then activation should spread automatically from these new concepts to other related concepts in the network (e.g., accipiter-eagle). However, Dagenbach, Horst, and Carr (1990) found that a newly learned word such as accipiter did not activate eagle at short SOAs (i.e., less than $250 \mathrm{msec}$ ) until after approximately 15 study trials over a 5-week period. Thus, the facilitation observed in the present experiments is, at least in part, likely attributable to the retrieval of the episodic pointer (e.g., hawk). Once the episodic trace points to the semantic representation, however, facilitation of related concepts is probably mediated by spreading activation within the semantic system.

Finally, the present results pose a puzzle concerning the conceptualization of semantic memory in terms of a spatial metaphor (e.g., Collins \& Loftus, 1975). The assumption underlying Experiment 2-and supported by the results of that experiment-was that associates and synonyms are encompassed within the same spatial model of semantic memory and that synonyms lie closer together, falling within the center of the center-surround mechanism, whereas associates lie farther away, falling within the surround. However, this also predicts that synonymous relations should generally show stronger priming than associative relations, but we can find no evi- 
dence for this prediction in the existing semantic priming literature. An alternative explanation for the difference between associates and synonyms is that synonyms are not part of the associative network and are instead represented in another dimension of semantic space. Further research is needed to clarify the position of synonyms in the semantic system.

\section{REFERENCES}

ANDERSON, M. C., \& BJork, R. A. (1993). Mechanisms of inhibition in long-term memory: A new taxonomy. In D. Dagenbach \& T. H. Carr (Eds.), Inhibitory processes in attention, memory, and language (pp. 265-325). New York: Academic Press.

Brown, A. S. (1979). Priming effects in semantic memory retrieval processes. Journal of Experimental Psychology: Human Learning \& Memory, 5, 65-77.

Brown, R., \& MCNEIL, D. (1966). The "tip-of-the-tongue" phenomenon. Journal of Verbal Learning \& Verbal Behavior, 5, 325-337.

CARR, T. H.. \& DagenbaCH, D. (1990). Semantic priming and repetition priming from masked words: Evidence for a center-surround attentional mechanism in perceptual recognition. Journal of Experimental Psychology: Human Learning \& Memory, 16, 341-350.

Collins, A. M., \& LofTus, E. F. (1975). A spreading-activation theory of semantic processing. Psychological Review, 8, 407-428.

Dagenbach, D., \& CARR, T. H. (1994). Inhibitory processes in perceptual recognition: Evidence for a center-surround attentional mechanism. In D. Dagenbach \& T. H. Carr (Eds.), Inhibitory processes in attention, memory, and language (pp. 327-357). New York: Academic Press.

Dagenbach, D., CarR, T. H., \& Barnhardt, T. M. (1990). Inhibitory semantic priming of lexical decisions due to failure to retrieve weakly activated codes. Journal of Experimental Psychology: Learning, Memory, \& Cognition, 16, 328-340.

Dagenbach, D., CarR, T. H., \& Wilhelmson, A. (1989). Task-induced strategies and near-threshold priming: Conscious influences on unconscious perception. Journal of Memory \& Language, 28, 412-443.

Dagenbach, D.. Horst, S., \& CaRr, T. H. (1990). Adding new information to semantic memory: How much learning is enough to produce automatic priming? Journal of Experimental Psychology. Learning, Memory, \& Cognition, 16, 581-591.

GLISKY, E. L. (1992). Acquisition and transfer of declarative and procedural knowledge by memory-impaired patients: A computer data-entry task. Neuropsychologia, 30, 899-910.

HinTZMAN, D. L. (1978). The psychology of learning and memory. San Francisco: W. H. Freeman.

Houghton, G., \& TiPPER, S. P. (1994). A model of inhibitory mechanisms in selective attention. In D. Dagenbach \& T. H. Carr (Eds.), Inhibitory processes in attention, memory, and language (pp. 53-112). New York: Academic Press.

Meyer, D. E., \& SchVaneveldt, R. W. (1971). Facilitation in recognizing pairs of words: Evidence of a dependence between retrieval operations. Journal of Experimental Psychology, 90, 227-234.

NeELy, J. H. (1977). Semantic priming and retrieval from lexical memory: Roles of inhibitionless spreading activation and limitedcapacity attention. Journal of Experimental Psychology: General, 106, 226-254.

NeELy, J. H. (1991). Semantic priming effects in visual word recognition: A selective review of current findings and theories. In D. Besner \& G. Humphreys (Eds.), Basic processes in reading: Visual word recognition (pp. 264-336). Mahwah, NJ: Erlbaum.

OLDFIELD, R. C. (1966). Things, words and the brain. Quarterly Journal of Experimental Psychology, 18,340-353.

Posner, M. I., \& SNyder, C. R. R. (1975a). Attention and cognitive control. In R. L. Solso (Ed.), Information processing and cognition The Lovola Symposium (pp. 55-85). Mahwah, NJ: Erlbaum.

POSNER, M. I, \& SNYDER, C. R. R. (1975b). Facilitation and inhibition in the processing of signals. In P. M. A. Rabbitt \& S. Dornic (Eds.), Attention and performance $V$ (pp. 669-682). New York: Academic Press.
Roediger, H. L., III, Neely, J. H., \& Blaxton, T. A. (1983). Inhibition from related primes in semantic memory retrieval: A reappraisal of Brown's (1979) paradigm. Journal of Experimental Psychology: Learning, Memory, \& Cognition, 9, 478-485.

Shimamura, A. P. (1985). Problems with the finding of stochastic independence as evidence for multiple memory systems. Bulletin of the Psychonomic Society, 23, 506-508.

TIPPER, S. P. (1985). The negative priming effect: Inhibitory priming by ignored objects. Quarterly Journal of Experimental Psychology, 37A, 571-590.

TipPeR, S. P., \& Cranston, M. (1985). Selective attention and priming: Inhibitory and facilitatory effects of ignored primes. Quarterly Journal of Experimental Psychology, 37A, 591-611.

TIPPER, S. P., \& DRIVER, J. (1988). Negative priming between pictures and words: Evidence for semantic analysis of ignored stimuli. Memory \& Cognition, 16, 64-70.

Tulving, E. (1972). Episodic and semantic memory. In E. Tulving \& W. Donaldson (Eds.), The organization of memory (pp. 381-482). New York: Academic Press.

Tulving, E., Hayman, C. A. G., \& Macdonald, C. A. (1991). Longlasting perceptual priming and semantic learning in amnesia: A case experiment. Journal of Experimental Psychology: Learning, Memory, \& Cognition, 17, 595-617.

WALLEY, R. E., \& Weiden, T. D. (1973). Lateral inhibition and cognitive masking: A neuropsychological theory of attention. Psychological Review, 80, 284-302.

WARRINGTON, E. K., \& MCCARTHY, R. A. (1988). The fractionation of retrograde amnesia. Brain \& Cognition, 7, 184-200.

Wiesel, T. N., \& Hubel, D. H. (1960). Receptive fields of ganglion cells in the cat's retina. Journal of Physiology, 153, 583-594.

\section{APPENDIX}

\section{A. Vocabulary Words, Definitions, and Associatively \\ Related Targets Used in Experiment 1}

accipiter-a hawk (eagle)

acomia-baldness (head)

aglet-plastic tip of a shoelace (foot)

aleger-in good spirits (mood)

alfin-bishop in a game of chess (rook)

anicular-feeble minded (smart)

annicut-a dam in a stream (pond)

arenose-sandy or sandlike (grain)

aubade-a morning love song (poem)

auricome-blonde (fair)

barrad-a dunce hat (corner)

batrachian-froglike (toad)

baxter-female baker (pastry)

belgard-a loving look (romance)

biffin-a dark red cooking apple (pie)

biggin-the mesh basket in a coffee percolator (brew)

bilch-a vigorous, healthy person (strong)

blebby-extremely sunburned (blistered)

brichins-caviar (expensive)

buccula-double chin (fat)

bucolic-anything to do with a rural lifestyle (urban)

burgoo-thick oatmeal (breakfast)

cere-to wax (car)

chewink-red-eyed sparrow (robin)

claviger-janitor (sweep)

coddum-a guessing game (question)

coom-dust behind a car on a dirt road (cloud)

coruscate-to sparkle (diamond)

coryza - a head cold (chills)

couvade-male labor pains (pregnant)

dacoit-member of a band of robbers (gang)

dorsom-the back of the tongue (throat) 
dromos-a course for running ( jog)

dudder-to confuse or stun with noise (shout)

eidolon-a specter or phantom (haunt)

emunctory-pertaining to blowing one's nose (tissue)

ern-to mourn or grieve (funeral)

estivate-to pass the summer (holiday)

exculpate-to prove innocent (judge)

fenerate-to lend with interest (borrow)

foulcher-a handbag (back pack)

foy-a feast for one who is about to leave (farewell)

gallipot-a small jar used by druggists (pills)

gelogenic-humorous (comedy)

gledge-to squint (bright)

goety-type of black magic (warlock)

grignet-partridge (pheasant)

gussock-a sudden gust of wind (blow)

haptic-pertaining to touch (rub)

henotic-perfect harmony (melody)

hucksum-hip bone (waist)

hustings-a political platform (vote)

hystricine-having to do with porcupines (needles)

illth-being poor (rich)

irenic-peaceful (violent)

joola-a rope bridge (swing)

kibe-a blister on the foot (sore)

kiddle-wicker fish trap (lobster)

krang-whale meat (ocean)

laddle-an elegant woman (queen)

langrets-loaded dice (cheat)

lonk-breed of English sheep (shepherd)

lythcoop-an estate sale (garage)

maffick-rejoice wildly (party)

mopus-small coin (silver)

musnud-padded cushion on a throne (king)

napery-household linen (sheets)

noop-the point of the elbow (arm)

nubbin-a tiny ear of corn (cob)

numnah-saddle cloth (riding)

oriel-a big bay window (view)

orison-a short prayer (hymn)

otiose-not moving (mobile)

pooks-small piles of hay (barn)

popliteal-hollow area behind the knee (bend)

proxenete-divorce lawyer (marriage)

quirt-a riding whip ( jockey)

ramekin-baking dish (oven)

repkie-edible sea urchin (starfish)

risible-capable of laughing (chuckle)

roker-foot long ruler (yard)

sambar-a deer with antlers (moose)

sarcle-to dig up weeds (rake)

sarwan-camel driver (desert)

scion-a descendant of a noble family (prince)

scruto-trapdoor in a stage (drama)

shawm-old-fashioned oboe (horn)

sinapize-to sprinkle with water (hose)

skuq-inkblot on paper (pen)

stannary-tin mine (coal)

stapple-stem of a pipe (cigar)

stilp-to walk around on stilts (balance)

syrt-quicksand (sink)

taboret-needlework frame (sewing)

tantony-the runt of a litter (tiny)

thrawn-twisted (pretzel) thwaite-land cleared of all growth (develop)

titbow-shimmering haze caused by heat (glare)

tresayle-a grandfather's grandfather (uncle)

trombash-boomerang (throw)

twibil-a two-edged axe (sword)

upeygan-black rhinoceros (elephant)

wapacut-a large white owl (wise)

whally-having eyes of a light color (grey)

B. Vocabulary Words, Definitions, and Synonymously

Related Targets Used in Experiment 2

abrosia-eating nothing (fasting)

accipiter-a hawk (falcon)

acicular-shaped like a needle (pointed)

agrote-eat too much (glutton)

aleger-in good spirits (happy)

anchoret-one who has become a recluse (hermit)

apricate-lie in the sun (bask)

bantling-a very young child (toddler)

beton-concrete (cement)

bever-food between meals (snack)

bibble-someone who drinks a lot (boozer)

blet-overripe (spoiled)

brisance-the shattering effect of an explosive (blast)

brumous-characterized by mist (foggy)

buldering-hot and humid (sweltering)

burgonet-helmet (headgear)

cadge-to beg (plead)

carfax-intersection of four or more roads (crossroads)

cark-to be anxious (fret)

caxon-a hairpiece (wig)

cerulean-light blue (azure)

chilliad-a thousand years (millenium)

claver-idle talk (rumor)

claviger-janitor (custodian)

coarct-to hold back (restrain)

colubrine-cunning (sly)

coom-dust behind a car on a dirt road (gravel)

coruscate-to sparkle (shimmer)

cozen-to win over (persuade)

cribble to pass something through a sieve (sift)

curple-buttocks (backside)

curtate-shortened (abbreviated)

dacoit-member of a band of robbers (thief)

daut-to fondle (caress)

dight-to put in order (arrange)

drecche-to vex or trouble (aggravate)

drintling-noises made by turkeys (gobble)

eidolon-a specter or phantom (ghost)

elrig-young woman (girl)

ensky-to immortalize a person (idolize)

eruct-to belch loudly (burp)

ettle-to be ambitious (aspire)

exculpate-to prove innocent (acquit)

fadge to do well at something (achieve)

feek-to wander around aimlessly (roam)

figulate-something made out of clay (pottery)

fleam-sharp knife used by veterinarians (scalpel)

foulcher - a handbag (purse)

fugacious-fleeting (brief)

fuscous-brown or black in color (ebony)

gelogenic-humorous (funny)

glunch-sullen frown (pout)

grignet-partridge (quail) 
groodles-extra food (leftovers)

gumpelfik-fidgety (nervous)

haffle-to stutter (stammer)

halsen-to foretell the future (prophesy)

hankin-put off unpleasant work (procrastinate)

hispid-having a rough texture (coarse)

hucksum-hip bone (pelvis)

illth-being poor (penniless)

imbosk-to hide something (conceal)

irenic-peaceful (tranquil)

iswonk-work hard (toil)

jink-to dodge by turning sharply (swerve)

keck-to throw up (vomit)

liturate-covered with spots (dotted)

maffick-rejoice wildly (celebrate)

manumit-to free (release)

marlish-laid back or easygoing (casual)

maugre-ill will (hatred)

maunder-incoherent talk (babble)

menseful-polite (courteous)

mickle-a large quantity (many)

minatory-menacing (scary)

mizzy-swamp (bog)

nikin-someone who is stupid (imbecile)

nithing-a cowardly person (sissy)

nunting-appearing clumsy (awkward)

nutate-to droop or bend downward (sag)

objurgate-to denounce or scold (condemn) olid-having a putrid smell (stink)

paletot-baggy overcoat (parka)

rabiator-a man who likes to fight (boxer)

rampelter-tall tale (myth)

sambar-a deer with antlers (buck)

sapidity-good tasting (yummy)

saxify-to turn something into stone (petrify)

sciolist-charlatan or faker (imposter)

scrump-something that is all shriveled up (withered)

scuddick-something of no value (worthless)

shoggle-to shove or shake (push)

sinapize-to sprinkle with water (spray)

sinciput-the forehead (brow)

sloom-to become weak and tired (weary)

smatchet-nasty little kid (brat)

snash-rude, abusive talk (insult)

snudge-a stingy individual (miser)

sorner-freeloader (bum)

thew-physical or muscular power (strength)

thingus-nobleman or knight (lord)

truckle-to give in (surrender)

votary-a fervent supporter (fanatic)

xystus-indoor exercise area (gym)

(Manuscript received May 20, 1994;

revision accepted for publication February 10, 1995.) 